\title{
O LUGAR DA PSICOLOGIA SOCIAL EM GEORG SIMMEL
}

\author{
Emerson Ferreira Rocha* \\ Ricardo Visser* *
}

\begin{abstract}
O artigo pretende trazer a discussão acerca do lugar da psicologia social na obra de Georg Simmel. O texto abordará a problemática a partir dos seguintes ângulos: a) a reconstrução geral do lugar da psicologia social na obra simmeliana; b) a apreciação do elo entre a emergência da cultura moderna e o adensamento psicológico da experiência individual; c) reconstruir como direções teóricas semelhantes são tomadas em sua teoria do valor, na qual sujeito e objeto se diferenciam por meio da distância entre o gozo e seu objeto; e, por fim, d) traçaremos como Simmel esteve preocupado em compreender a dialética entre sujeito e objeto a partir de uma ótica capaz de relacionar cognição e pulsão. Espera-se que este debate esclareça o significado sociológico do interesse de Simmel pela psicologia por meio da teoria do desenvolvimento cultural, da gênese dos valores e da personalidade.
\end{abstract}

PALAVRAS-CHAvE: Teoria sociológica. Psicologia social. Georg Simmel. Cultura moderna. Personalidade.

\section{INTRODUÇÃO}

Entre os autores clássicos, Georg Simmel foi um dos que mais refletiu sobre o significado da psicologia para a sociologia. Segundo o autor em questão, a psicologia deve lutar contra sua tendência de isolar a categoria de indivíduo, atomizando-o: psicologia social sim, solipsismo não. Defendemos a ideia de que as análises de cunho psicológico do autor não consistem em "teses artisticamente formuladas”, como sugere Weber em uma de suas apreciações da obra de Simmel (Nedelmann, 1988, p. 13-15). Procuraremos recolocar o itinerário da dimensão social psicológica como atrelado à elaboração do conceito de interação (Wechselwirkung). Sob este prisma, as interações constituem a dinâmica que obriga sen-

* Universidade de Brasília (UnB). Departamento de Sociologia.

Campus Universitário Darcy Ribeiro, s/n - Prédio do ICS - Asa Norte. Cep: 70910-900. Distrito Federal - Brasília Brasil.erochedo@gmail.com

https://orcid.org/0000-0001-8007-367X

* * Universidade Federal de São João del-Rei (UFSJ). Departamento de Ciências Sociais.

Praça Dr. Augusto Chagas Viegas, 17. Largo do Carmo. Cep: 36300-088. São João del-Rei - Minas Gerais - Brasil. ricardovis@gmail.com

https://orcid.org/0000-0002-5519-9606 timentos, emoções, motivações e interesses a se projetarem em um contexto, ou seja, a passarem por um processo de objetivação no qual conquistam seu significado sociocultural, além de se deixarem equiparar ou contradizer por outras exteriorizações afetivas operadas por outros indivíduos. Portanto, pode-se crer que estados afetivos e emocionais são passíveis de tornarem-se comensuráveis. Como consequência deste processo de objetivação de motivações psíquicas, a troca (Tausch) (Simmel, 2009) não prescinde de uma dimensão cognitiva tampouco de uma energização afetiva e pulsional.

$\mathrm{O}$ artigo se divide em quatro partes: a) uma reconstrução geral do lugar da psicologia social na obra simmeliana; b) uma apreciação do elo entre a emergência da cultura moderna e o adensamento psicológico da experiência individual; c) também veremos como direções teóricas semelhantes são tomadas em sua teoria do valor na qual sujeito e objeto se diferenciam por meio da distância entre o gozo (Genuss) e seu objeto (Simmel, 1896a, 2009); d) por fim, traçaremos como Simmel esteve preocupado em compreender a dialética entre 
sujeito e objeto a partir de uma ótica capaz de relacionar cognição e pulsão. Nesse momento, é importante ter em mente que os anseios não permanecem presos ao âmbito privado da vida mental, pois eles se tornam alvo de um processo de objetivação coletivamente mediado. Para tanto, faz-se necessário formular uma teoria da personalidade que não se dilua na interação, que não se reduza a um epifenômeno da vida pulsional instintual e que tampouco se limite à expressão direta do sentido consciente dotado pelo próprio indivíduo.

O intento geral do artigo é demonstrar que há uma preocupação sistemática na obra de Simmel em definir sociologicamente o significado do teor afetivo e esquematizações cognitivas envolvidas no jogo interacional. Espera-se que esta reconstrução esclareça o significado sociológico de seu interesse pela psicologia por meio da teoria do desenvolvimento cultural, da gênese dos valores e da personalidade.

\section{RETRAÇANDO O LUGAR DA PSI- COLOGIA SOCIAL NA OBRA DE GEORG SIMMEL}

A tentativa de compreensão sobre o lugar da psicologia social na obra simmeliana passa pelo crivo crítico de seus contemporâneos. Um deles, Max Weber, observava as análises de cunho psicológico de Simmel com desconনิ fiança. Além de censurar Simmel por não ter o. distinguido claramente economia monetária e capitalismo (Nedelmann, 1988), Weber o acusa ¿े de elaborar suas análises sob a égide do "psico今 logismo”, borrando o caráter lógico do conceito $\rightarrow$ de compreensão (Verstehen). Segundo Weber, ले o que importa é o efeito prático de interesses

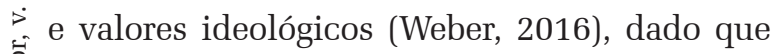
se cristalizam em formas típicas de ação, mas não sua motivação psíquica. Ademais, para Weber, a interpretação (Deutung) do sentido de um enunciado pelo agente ocorre apenas quando o conteúdo não é imediatamente compreendido (uma ordem mal compreendida, por exem- plo). Já em Simmel, a interpretação refere-se não apenas ao significado do enunciado, mas também às motivações do falante (Nedelmann, 1988). Weber (2016) identifica duas vertentes na interpretação: a) a que consiste na expressão avaliativa perante um objeto ou situação, como a apreciação de uma obra de arte; e b) a que se consolida como inclinação a um juízo que vem a reconhecer o nexo real (e relacional) compreendido como válido. Weber se centra nos aspectos lógicos e enunciativos da interpretação: o sujeito vem a tomar uma posição ao mobilizar conceitos valorativos.

Em contraste, Simmel propõe a investigação não apenas sobre o que é dito (o enunciado), mas igualmente acerca dos estados psíquicos do emissor, arrolando a vida mental (Seelenleben) $)^{1}$ (Simmel, 2006) como fator integrante das interações intersubjetivas. Trata-se de perquirir não apenas o sentido lógico de um enunciado, atribuído enquanto sentido subjetivo da ação, mas tematizar a origem psicológica deste enunciado. Da mesma maneira, compreende-se um contraste entre os tipos ideais de Weber, que correspondem a sínteses lógicas, e os tipos sociais de Simmel, que correspondem a padrões sociopsicológicos. Apenas em sua acepção particular de tipo de conduta humana (Aron, 1993), os tipos ideais de Weber se aproximam dos tipos sociais de Simmel.

Além disso, no tocante ao átomo da pesquisa sociológica, vale notar que o conceito de ação social em Weber difere substancialmente da categoria de interação. Esta última alicerça-se em pressupostos explicitamente intersubjetivos, isto é, no mínimo dialógicos (Kracauer, 1977; Simmel, 2013), enquanto a categoria weberiana de ação social adere explicitamente ao individualismo metodológico. Quanto à obra de Weber, vale estabelecer uma diferença entre individualismo metodológico e individualismo ontológico, sendo que este último não marca especialmente o trabalho do

${ }^{1}$ Vale notar que a definição da palavra no dicionário engloba pensamentos, sensações e sentimentos. Cf. Grosswörterbuch (2011, p. 1253). 
autor. Com efeito, do ponto de vista ontológico, Weber se interessa especialmente por cosmovisões enquanto construtos culturais, cuja eficácia histórica está vinculada ao suporte que encontram em coletividades. A primazia dada ao estudo do sentido da ação individual ocorre como meio para o estudo das cosmovisões, cuja relevância sociológica repousa nesse seu caráter de orientação coletiva. Em Weber, a ênfase no indivíduo é antes metodológica, ela constitui, sobretudo, um método de chegada às cosmovisões ou ao sentido propriamente social das ações de maneira geral.

Isto se justifica em função de Max Weber localizar o liame indivíduo/sentido/ação social como molécula básica de sua sociologia compreensiva (Sell, 2016). Já para Simmel, o princípio da ação com relação a fins (Zweckhandeln), por exemplo, repousa na própria interação, dado que o sucesso de uma ação conscientemente planejada suscita uma cadeia de reações subsequentes. Como coloca o autor: "O sentido fundamental da ação com relação a fins repousa na interação a qual a institui entre sujeito e objeto. Na medida em que, de antemão, o simples fato de nossa existência nos entrelaçar nesta interação, a ação determinada por fins a eleva na interioridade do espírito" (Simmel, 2009, p. 292, tradução nossa). ${ }^{2}$

Inicialmente, o interesse de Simmel por temas relacionados à psicologia social advém de seu contato com a psicologia dos povos (Völkerpsychologie), considerada como um estágio inicial da sociologia por congregar áreas do conhecimento, como linguagem, etnologia, psicologia e suas conexões com certa formação do temperamento coletivo, normalmente associada a Wilhelm Wundt (Frisby, 1992). Outros expoentes, como Moritz Lazarus e Heymann Steinthal, influenciaram a inclinação de Simmel. No entanto, o incomodava a noção hipostasiada de mentalidade do povo (volksseele),

${ }^{2}$ No original: "Die prinzipielle Bedeutung des Zweckhandelns liegt also in der Wechselwirkung, die es zwischen dem Subjekt und dem Objekt stiftet. Indem schon die bloße Tatsache unserer Existenz uns in diese Wechselwirkung verwebt, hebt das zweckbestimmte Handeln sie in die Innerlichkeit des Geistes". proposta por Gustav Fechner, ou a ideia de uma antropologia substantiva, formulada por Herbert Spencer (Frisby, 1992).

Simmel não almejava entender a unidade lógica da ação individual, tampouco as regularidades formadoras da psique (mentalidade) de um povo. Seus esforços orientavam-se então à apreensão da oscilação e do jogo de forças que compõem as interações intersubjetivas, as quais podem ser reconduzidas à formas de sociações (Vergesellschaftungen) (Simmel, 1992). Assim, embora possam emergir em circunstâncias empíricas discrepantes, diferentes fenômenos interativos (conteúdos) podem ser classificados dentro de uma forma lógica comum. Portanto,

\begin{abstract}
é possível, de um lado, verificar que a mesma forma de sociação emerja - para diferentes finalidades - num conteúdo bem diferente e, de outro lado, que o mesmo interesse substancial possa aderir a diferentes formas de sociação, como em seu portador ou em seu modo de realização - assim como as mesmas formas geométricas podem ser encontradas nas mais diversas substâncias (Simmel, 1992, p. 21, tradução nossa). ${ }^{3}$
\end{abstract}

Com efeito, na fundamentação de sua sociologia, Simmel admite que seu itinerário de pesquisa nada mais é do que um capítulo da psicologia social e que sociações são primariamente fenômenos psíquicos, dado que todo evento social ocupa um lugar na vida psíquica dos indivíduos (Simmel, 1992). Todavia, tudo indica que, sob a ótica de Simmel, tanto a vida psíquica quanto a carga psicológica que permeia os fenômenos associativos não constituem realidades estanques. Não nos parece que o autor em questão recaia sobre uma concepção dualista. O fato é que fenômenos psíquicos apenas ganham relevância para o sociólogo à medida que adquirem significado na realidade objetiva das sociações (Frisby, 1992).

${ }^{3}$ No original: "Es muss sich einerseits finden, dass die gleiche Form der Vergesellschaftung an ganz verschiedenem Inhalt, für ganz verschiedene Zwecke auftritt, und umgekehrt, dass das gleiche inhaltliche Interesse sich in ganz verschiedenen Formen der Vergesellschaftung als seine Träger oder Verwirklichungsarten kleidet - wie sich die gleichen geometrischen Formen an den verschiedensten Materien finden". 
Conclui-se, portanto, que a psicologia social, tomada como material e meio para a pesquisa social não se ocupa de processos intrapsíquicos em indivíduos isolados, mas daqueles que se projetam no contexto prático das interações (Simmel, 1992). Por este motivo, Simmel advoga a ideia de que o tratamento científico de processos psíquicos não repousa necessariamente em procedimentos da psicologia individual (Simmel, 1992).

Em relação ao possível sentimento de intenso ódio entre parentes de sangue, por exemplo, o autor postula que o cientista social deve se atentar não ao encadeamento psíquico operante em cada indivíduo, mas observar sua síntese sob as categorias de adesão (Einung) ou ruptura (cisão) (Entzweiung) (Simmel, 1992). Ou seja, estados afetivos adquirem significado eminentemente sociológico, ao passo que produzem, reproduzem ou cessam interações no decorrer do tempo. Portanto, a finalidade da análise sociológica é a compreensão de como processos psíquicos se refletem na concretude da sociação, como um drama que do início ao fim contém processos psíquicos de seus personagens, mas cuja trama não reside no conhecimento psicológico restrito e sim nas sínteses produzidas nos contextos interativos, assim como no gênero literário trágico (Simmel, 1992). O sentimento de lealdade a um partido ou à esposa/ao marido é resultante de sucessivas interações, bem como a gratidão é o sentiปิ mento decorrente da troca (Nedelmann, 1988). o Dentro deste espectro, fica clara a distância entre a concepção simmeliana e o conceito de mentalidade do povo, ou mesmo a ideia de uma consciência da sociedade (Ne$\therefore$ delmann, 1988). A seu ver, o grande problema ले destas abordagens holistas reside justamente

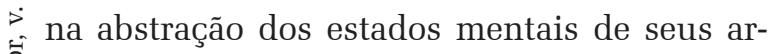
ranjos prático-sociativos, acoplando estados afetivos, psíquicos e traços do caráter a um tipo médio coletivo. Este movimento teórico fatalmente incorreria em uma categoria hipostasiada de sociedade, tomada enquanto totalidade objetiva unitária.
Se para Simmel a psicologia social se interpenetra com o método sociológico, uma vez que processos psíquicos adquirem significados em circunstâncias interacionais, sua intenção aponta para uma forma original de mediação entre indivíduo e sociedade. Por um lado, nem a sociedade é uma totalidade lógica (ou uma entidade substantiva) tampouco os indivíduos são mônadas encerradas em si mesmas, que, então, vêm a interagir. Em certo sentido, compreendemos as reservas de Simmel em tratar o fato social como coisa (Durkheim, 2008), é preciso tratá-lo enquanto teias de forças e relações significativas. Ao tentar superar a oposição entre holismo e individualismo metodológico, Simmel entende que os processos de objetivação das interações acontecem de maneira gradual, sendo as interações uma condição necessária da sociedade (Vandenberghe, 2005). Se a objetivação, institucionalização e a estabilização das interações são processos e dinâmicas paulatinas, não há nenhuma cláusula necessária ou lei social que as impeça de, em determinado momento, regredirem ou se desestabilizarem.

O modo paulatino de objetivação jamais exclui o agente, o que é visível em sua perspectiva sobre a cultura subjetiva como incessante dialética entre apropriação do legado intelectual proporcionado pela cultura objetiva. Por isso, a cultivação não é propriamente o virtuosismo alcançado exclusivamente via esforço subjetivo e pessoal, ou a apropriação fragmentada de conhecimentos especializados. A cultivação ocorre quando a cultura subjetiva é submetida ao intercâmbio crescente com normas sociais, valores e formações espirituais objetivas em campos como a moral, a técnica, a ciência, a arte etc. (Simmel, 2005).

Se processos psíquicos são operantes em interações entre indivíduos, a sociologia possui pressupostos psicológicos. Tais pressupostos interessam a Simmel, sobretudo, em fenômenos interativos de caráter fragmentário, acidental e instável nos quais, comumente, prevalece um baixo nível de institucionali- 
zação e estruturação, remetendo a interações face a face (Frisby, 1992). A ideia de que a modernidade traz consigo a aceleração e, ao mesmo tempo, a estabilização dinâmica das relações sociais e instituições (Rosa, 2005), leva Simmel a crer que fenômenos aparentemente fragmentados e acidentais poderiam revelar um significado profundo sobre a cultura moderna (Frisby, 1992). Assim, a construção de uma teoria sociológica não poderia renunciar à profunda influência de um diagnóstico da modernidade. Por sua combinação peculiar entre dinâmica e estabilização, estruturação e erosão, a modernidade acabaria servindo como caso paradigmático para o desenvolvimento de uma teoria sociológica geral de caráter genético, quer dizer, preocupada sempre com o social em status nascendi (Frisby, 1992).

A análise sociológica de tais interações fugazes é mais fecunda em nível microssocial, no qual os estados psíquicos e o vernáculo social psicológico ganham destaque. Na esteira da necessidade de capturar eventos interativos fugidios, incapazes de serem simplesmente reconduzidos a alguma lei social, emerge o ímpeto de aplicar a sociologia a searas da vida social eminentemente perpassadas por emoções: família, relações matrimoniais, amorosas, de amizade (Nedelmann, 1988). Isso não significa que Simmel defenda unilateralmente uma microssociologia. Em nenhum momento o autor recusa o status de realidade e a relevância de formas em nível macrossocial, de instituições como o Estado, por exemplo. A questão é que Simmel coloca a análise das interações menos estáveis como um contraponto heurístico capaz de colocar em suspenso, do ponto de vista da análise, o caráter de opus operatum dessas grandes formas. Ao oferecer a oportunidade para o desenvolvimento de uma sociologia voltada ao estado nascente das formas, a microssociologia daria os recursos para recobrar a contingência constitutiva das instituições, mesmo das mais reificadas.

Por fim, sublinhamos, como percebe Heinz-Jürgen Dahme, Simmel nunca se preo- cupou em desenvolver uma terminologia sociológica pura, admitindo constatações psicológicas em investigações sociológicas (Frisby, 1992). Advertimos, todavia, que isso não significa a redução de sua sociologia à psicologia, ou que Simmel não tenha desenvolvido conceitos verdadeiramente sociológicos. Pelo contrário, a incorporação de enquadramentos conceituais da psicologia social se justifica porquanto a matéria empírica sociológica se apresenta de imediato nos indivíduos como processos psíquicos, que, em primeira mão, são apreendidos sob conceitos psicológicos, mas cujo significado sociológico deve ser retrabalhado por meio de categorias como interação e sociação. É apenas na externalização das motivações psíquicas em interações intersubjetivas - as quais passam pela adequação forçada aos contextos de interação perante outras motivações, valores e interesses objetivados - que tais estados afetivos podem se tornar objetivamente comensuráveis. A dinâmica intersubjetiva das interações cria sentimentos de segunda ordem, ou seja, sentimentos sociais (soziale Gefühle) que não anulam necessariamente a presença de estados afetivos intraindividuais (Nedelmann, 1988).

Para Simmel, o advento da cultura moderna se entrelaça com o adensamento psicológico da experiência individual. De modo geral, a cultura é aquilo que distingue o ser humano dos animais. Contudo, em sua ótica, ela consiste muito mais em um processo do que a simples emergência da vida simbólica, dos costumes, das normas morais e dos valores. É a cultura que instaura a dialética entre sujeito e objeto (Simmel, 2005), visto que seus conteúdos se autonomizam com relação à cultura subjetiva, mas, ao mesmo tempo, se encontram forjados nela. Logo, o indivíduo temporalmente finito pode vir a contribuir para o enriquecimento da cultura objetiva, mas essa última goza de uma estabilidade em relação às instabilidades e variações da cultura subjetiva. Talvez seja exatamente por seu cerne dinâmico e relacional que Simmel prefira o conceito de cultura ao de sociedade, no sentido de uma totalidade objetiva acabada. 
Os argumentos sociogenéticos de Simmel se orientam pelo prisma das condições de possibilidade para uma dada configuração de interações se estabilizar temporalmente, sedimentar sociações em instituições e, em última análise, aproximar-se de sua forma abstrata e típica. Assim, em termos da teoria geral das sociações, interações exercem uma nada desprezível influência sobre a vida mental. Como o autor postula: "Enquanto problema social psicológico, resta justificar: qual modificação o processo mental de um indivíduo experimenta, quando este processo ocorre sob determinadas influências do ambiente social?" (Simmel, 1992, p. 630, tradução nossa). ${ }^{4}$ Objetivações são sucedidas por subjetivações. Ainda, o nexo entre o conceito de cultura e o adensamento psicológico da experiência individual também pode ser encontrado no diagnóstico da modernidade de Simmel. Seu significado histórico, antropológico e metafísico reside na complexificação dos meios, proporcionando uma evolução cultural, mas, ao mesmo tempo, reside aqui o cerne de sua crítica aos processos de reificação, à elevação dos meios ao estatuto de fins.

A primazia dos meios sobre os fins enfatiza o significado eminentemente técnico da vida moderna, como se os resultados dos avanços tecnológicos tivessem um valor em si mesmos (Simmel, 1990). As culturas complexas não reduzem a atividade social ao trinômio desejo - meio - fim, mas a um encadeamento ปิ sucessivo e longo de meios cujo entrelaçamen$\sigma_{0}^{-}$to nem sempre é imediatamente apreensível (Simmel, 1990). Dado o caráter deveras longínđิ quo dos fins com relação à amplitude do enca$\neg$ deamento dos meios eficazes, a vida moderna ¿. supervaloriza a técnica, pois a articulação do கீ sentido dos fins não é possível, a cada momen-

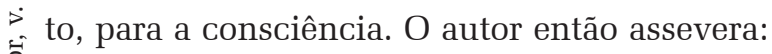
"Através do caráter longínquo da sucessão dos fins, os quais transformam a vida num proble-

${ }^{4}$ No original: "Als socialpsychologisches Problem also bleibt legitimierweise dies bestehen: welche Modifikationen erfährt der seeliche Prozess eines Individuums, wenn er unter bestimmten Beeinflussungen durch die gesellschaftliche Umgebung verläuft?". ma técnico, torna-se absolutamente impossível reter, a cada momento na consciência, o componente final de cada série" (Simmel, 1990, p. 42, tradução nossa). ${ }^{5}$ Com isso, a consciência prática projeta suas energias nos meios (nos próximos passos para atingir uma meta), de modo que o objetivo final se afunda atrás do horizonte visível (ou seja, passível de reflexão e avaliação) (Simmel, 1990). Deste enunciado extraem-se duas conclusões. A primeira é uma mudança de perspectiva destacando o valor mormente utilitário e materialista dos objetos, empobrecendo a cultura subjetiva: "o valor material que habita o interior das coisas aumentou mais velozmente do que o valor interior dos Homens" (Simmel, 1990, p. 9, tradução nossa). ${ }^{6}$ A segunda ilação é que a impressionante evolução técnica trazida pela modernidade não foi acompanhada por uma evolução moral à sua altura, incorrendo no sistemático apagamento da questão social (Simmel, 1990).

Com efeito, na modernidade, a elevação dos meios a fins esvazia do plano ontológico-social o caráter substantivo assentado em valores últimos, ao qual o ordenamento religioso das culturas pré-modernas estava ligado. O exemplo do dinheiro na cultura moderna (Simmel, 2005) é o mais contundente: sem um sentido qualitativo intrínseco (um reles meio de troca quantitativo), ele se torna em sua forma de capital o fim máximo da interação econômica. A riqueza monetária conduz não a um destino em que se encontra a plenitude (a graça divina ou sinais de salvação), mas a uma etapa não peremptória de nossas trajetórias. Por isso, o significado moderno do enriquecimento pessoal é sua indefinição, porquanto o lucro reconduz incessantemente à competição e à rearticulação dos meios eficazes para lucrar ainda mais. Para a personalidade, esta configuração cultural se reflete em perda de senti${ }^{5}$ No original: "Durch diese Langsichtigkeit der Zweckreihen, die das Leben zu einem technischen Problem macht, wird es uns tausendfach unmöglich, das Endglied jeder Reihe in jedem Augenblick im Bewusstsein zu haben”.

${ }^{6}$ No original: "Der den materiellen Dingen innewohnende Wert ist wesentlich schneller gestiegen als der innere Wert der Menschen". 
do, dado que a forma de valor quantitativa do dinheiro não fornece elementos para dotar a própria vida de significado pleno. Daí o caráter marcadamente mundano e secular do estilo de vida burguês, fazendo-se ressoar em temáticas como a moda, a lascividade da prostituição, a permissividade do luxo e a tendência à leviandade intelectual (Simmel, 2009).

O elo entre a singularidade da cultura moderna e o aprofundamento da experiência psicológica pode ser ainda observado na passagem da fusão entre personalidade e organização (guildas e corporações medievais, por exemplo) ao vínculo de pertencimento baseado na concorrência, no trabalho especializado, no desempenho impessoal e na diferenciação social, predominantes na modernidade (Simmel, 1992; 2009).

Nas guildas e corporações medievais, o indivíduo não pertence a nenhum outro círculo, estando sujeito aos interesses imediatos da organização e da comunidade. Assim, o pertencimento social exibe características destacadamente monistas. Por seu turno, o pertencimento moderno envolve algum grau de liberdade pessoal, dado que os vínculos com os círculos sociais se diversificam, tornando-se parciais (Simmel, 1992). Com isso, o indivíduo pertence, cada vez mais, de modo parcial a um círculo ou esfera social, posto que a personalidade não se torna abrangida em sua totalidade.

Simmel analisa como os círculos humanistas da renascença transcenderam relativamente o isolamento dos círculos medievais, até então calcados marcadamente pelo estamento de origem, e proporcionaram às pessoas de origens heterogêneas, que frequentemente permaneciam leais aos seus ofícios, a participação passiva ou ativa em ideias e conhecimentos que lhes perpassavam das mais diversas maneiras (Simmel, 1992). Isso permitia à personalidade facetar e recombinar a cultura objetiva a sua maneira, além de aderir a valores e ideais que se generalizam para além do pertencimento a um círculo social restrito.
Note-se que, embora atravessado por conflitos internos, o pertencimento parcial do "Eu" não conduz à fragmentação, mas à solidificação da consciência de si como unidade autônoma e singular (Simmel, 1992). Com o advento da pluralização dos vínculos de pertencimento - uma vez que a participação se torna parcial em esferas como família, trabalho, política, cultura etc -, se apura a ciência de si como alguém com destino próprio e singular. Ou seja, esta definição do Eu como instância relativamente autônoma diante das regras sociais que nos coagem é concomitante à diferenciação dos vínculos sociais.

Aqui, Simmel critica a antiga psicologia, que buscava definir a essência da mente antes de sua emergência enquanto fenômeno científico (Simmel, 1989). A unidade psíquica, então, deve ser tratada em termos relativos e funcionais (Simmel, 1989). Nesse âmbito, tal unidade depende, antes de tudo, de necessidades práticas (Simmel, 1989), de sociações, de códigos de conduta que nos obrigam a agir como os outros e de regras institucionalmente objetivadas que padronizam minimamente nosso comportamento.

Dessa forma, os atributos definidores da experiência psicológica não constituem uma unidade lógica precedente aos vínculos coletivos que a definem, muito embora possamos nos contrapor às instituições e aos valores dominantes, já que os vínculos de pertencimento baseados na complementaridade diferencial envolvem algum grau de reserva pessoal. Não por acaso, Simmel admite aspectos sociais e extrassociais da subjetividade, posto que, nestas circunstâncias, ela é capaz de estabelecer fronteiras entre o Eu e o mundo, ao almejar a autossuficiência (Bueno, 2019). Assim, romantismo e liberalismo, racionalismo e vitalismo - que em obras tardias vem a ser chamado de individualismo germânico (Bueno, 2019; Simmel, 1995) - surgem como correntes de pensamento que buscam fornecer uma resposta, ou pelo menos narrativas, a este novo espaço psicossocial. 
A relação entre os desdobramentos da dialética entre cultura subjetiva e cultura objetiva - dentre os quais se localiza a emergência do individualismo moderno -, mediada pelas interações, está relacionada a uma teoria do desenvolvimento cultural em Simmel. Como sustentado, a cultura é, para o autor, de natureza notadamente processual e evolutiva. O organismo (Simmel, 1896a) - que é uma unidade individual e, portanto, um indivíduo em sentido fraco, quer dizer, uma unidade discreta de vida - passa por sociações e interações, tornando-se gradualmente um indivíduo no sentido forte, ou seja, um organismo que a subjetividade se compreende como unidade autônoma e dotada de sentido. Portanto, o processo de desenvolvimento cultural, em Simmel, coincide com processos de individualização.

Enriquece-se, então, igualmente a experiência psicológica do Eu. Este ciclo da diferenciação social e psicológica é tão mais intenso quanto mais complexa e diferenciada é a cultura, ao passo que formações culturais mais simples se baseiam na identidade entre organismo e grupo (Simmel, 1989). A contraparte do ciclo de individualização do organismo é, ao nível da cultura objetiva, a diferenciação social e a correlata capacidade de conciliar um conjunto de valores e visões de mundo muitas vezes discrepantes. O mesmo ocorre a ní- do-se ao futuro abstrato (Zukunftbeziehung) (Simmel, 1989). Desse modo, nas culturas complexas, a educação e os processos de socialização visam o aproveitamento útil de impulsos transgressores e imorais (unsittlich) (Simmel, 1989), podendo vir a se projetar até mesmo de modo criativo. Os elementos da cultura se tornam mais complexos e elaborados: o encadeamento teleológico dos meios torna-se mais extenso (Simmel, 2009), a circulação dos conteúdos culturais torna-se cada vez mais intelectualizada, estimulando a própria condensação e compressão do significado de seus conteúdos a partir de sistemas de signos cada vez mais abstratos (Cohn, 1998; Simmel, 2009).

Portanto, culturas mais intelectualizadas, capazes de condensar sentido, exigem um poder de síntese mais apurado da consciência. Conquanto tenha analisado os desdobramentos da reificação, Simmel observa que é inegável que a forma quantitativa do valor, penetrando de maneira cada vez mais capilar nas trocas cotidianas pela força do dinheiro, exija da consciência maior poderio sintético (Simmel, 2009).

A Figura 1 procura ilustrar como a noção de desenvolvimento da cultura, que está no âmbito da Sociologia Geral de Simmel, se articula com a sua proposta de Sociologia Formal ao nível das sociações: vel da personalidade: quanto

mais refinada ela é, mais inde-

$\vec{\delta}$ pendentes se tornam seus im-

o pulsos e interesses (Simmel,

1989). Por isso, as culturas

\& mais desenvolvidas obedecem

רै ao princípio da diferenciação

$\dot{2}$ social, ocasionando uma divi-

लि são do trabalho capaz de esti-

$>$ mular a complementaridade funcional (Simmel, 1989).

Há também uma modificação no tocante às regras, que de simples sanções, passam cada vez mais a regular o comportamento, projetan-
Figura 1 - Noção de desenvolvimento da cultura articulada à Sociologia Formal ao nível das sociações

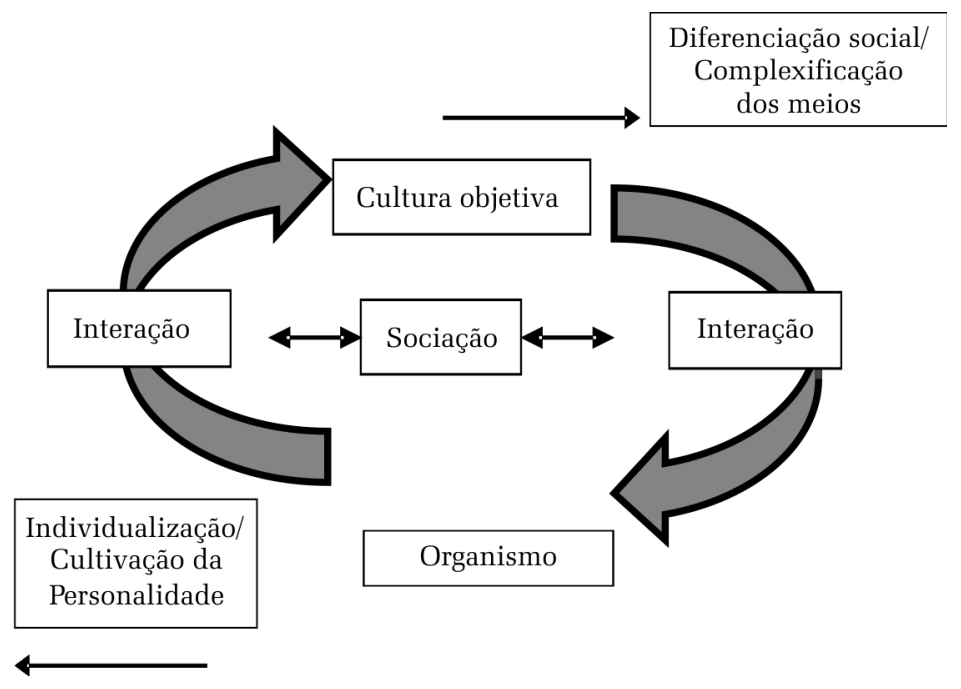


A psicologia social está na articulação entre esses dois planos de análise. É mediante o desenvolvimento que o organismo passa pelos processos de individualização. A contraparte desses processos de individualização do organismo é, no nível da cultura, a diferenciação. O desenvolvimento é o resultado desse ciclo, ou melhor, consiste nesse ciclo. Pode-se observar uma componente teleológica calcada nas ideias de individualização e de diferenciação, de modo que esses processos seriam positivos do ponto de vista de uma finalidade ideal do gênero humano, de sua "evolução". Contudo, essa perspectiva teleológica não é absoluta em Simmel, uma vez que ele também vê o desenvolvimento enquanto produtor de resultados que não se coadunam com uma ideia de aprimoramento, como se vê em suas discussões sobre a tragédia da cultura.

Com efeito, segundo Simmel, a consequência do desenvolvimento cultural e psicológico é a existência de duas tendências observáveis na modernidade: a) de um lado, a cultivação, ou seja, a apropriação ativa da cultura objetiva pela cultura subjetiva, gerando, por conseguinte, uma cultura objetiva mais sensível aos seus próprios fins, que remetem, postula Simmel, a uma ideia romântica de cultivação; b) noutro flanco, uma dialética trágica entre as culturas subjetiva e objetiva. O que Simmel observa, com o advento do capitalismo moderno, é uma primazia da especialização funcional sobre a cultivação, sendo a última ancorada no ideal romântico da Bildung.

Sob o prisma da primeira tendência, a cultura objetiva não pode constituir-se como uma obra reificada, alheia às consequências da ação humana. O ideal da cultivação procura o engrandecimento diferencial e vertical da interioridade e das potencialidades criativas da personalidade mediante a apreensão e a apropriação dos conteúdos acumulados na cultura objetiva. Há uma profunda aliança entre educação e a cultivação de valores pessoais.

Em contraste, a especialização funcional da divisão do trabalho, com sua reaplica- ção incessantemente instrumental de conhecimentos, não se relaciona senão de maneira fragmentada e superficial com o Eu, já que objetiva responder a uma demanda externa ou um imperativo funcional (na economia, na política, no direito etc.) (Simmel, 2005). De modo geral, a tragédia da cultura moderna nos faz reféns de uma interação e uma socialização com a cultura, obrigando-nos crescentemente a nos tornarmos especialistas profissionais, de modo a responder às exigências dos meios, elevados a fins objetivados (dinheiro, por exemplo). Daí o crescente caráter instrumental da incorporação do conhecimento e dos conteúdos culturais. Não por acaso Simmel (2009) nota a transição do conceito de formação do século XVIII ao XIX: a formação, primeiramente pensada como incorporação de valores pessoais e expansão da interioridade, passa a ser substituída pela instrução e pelo treinamento. Leopoldo Waizbort (2015) notou algo na mesma direção quando apontou a erosão do modelo humboldtiano de universidade, pensada como instituição autônoma e autárquica. Ao ceder espaço a um modelo atinado aos imperativos do mercado, a universidade passa a exigir intensamente uma apropriação estritamente pragmática e técnica do conhecimento. Nesta seara, o ideal do aprendizado como instrução subentende que o indivíduo cumpre procedimentos previamente estipulados, sem que as habilidades envolvidas em sua tarefa venham a transformar sua relação com o mundo, consigo e com os outros - ou seja, seus valores pessoais.

Simmel demonstra então, a partir dos temas aqui examinados, que o desenvolvimento cultural moderno, de um lado, abre espaço para o adensamento da experiência psicológica do indivíduo por meio, por exemplo, de vínculos que envolvem a liberdade pessoal e a cultivação. Por outro lado, a hipertrofia de uma divisão do trabalho cada vez mais sedimentada na especialização, baseada no ideal pedagógico da instrução e do treinamento, constitui fatores sociais que empobrecem o aprofundamento da interioridade. Contudo essa oposição 
não leva ao apagamento da dimensão psicológica das interações. Pelo contrário, ela consiste num plano analítico fundamental para a compreensão dos caminhos e descaminhos de nossa experiência na modernidade. Enquanto o valor moral da Bildung informa seus juízos sobre a tragédia da cultura moderna, Simmel mobiliza a psicologia social como instrumento auxiliar para a compreensão de como valores em geral emergem na vida cultural.

A diferenciação entre sujeito e objeto é aquilo que permite a emergência do valor. Ao postular uma teoria do valor, nosso autor não se apoia em premissas econômicas, mas em teses que apontam para como a objetivação de anseios (Begehren), de impulsos e da estima (Schätzung) se cristalizam em valorações (Wertungen). Em sua ótica, a sensibilidade às diferenças (Unterschiedsempfundlichkeit) constitui a base de toda valoração. Isto é: valoramos os objetos na medida em que os distinguimos (Simmel, 2009). Todavia, as motivações psíquicas dos indivíduos não se objetivam por si, mas por meio de atribuições inteligíveis, que passam por um processo de adequação, já que os outros também produzem valorações (Vandenberghe, 2005). Assim, enquanto relações energizadas por valorações, interações são capazes de socializar, mesmo quando envolvem conflito e subjugação (Simmel, 1992).

O grande problema de uma teoria do valor derivada exclusivamente de relações de interస્ડ câmbio econômico é que seu assentamento em ơ convenções simbólicas e culturais não é investigado, sendo o próprio processo de formação do valor tomado simplesmente como um dado (Boudon, 1993). Com isso, reduz-se o valor das ¿. mercadorias à funcionalidade do seu uso instruґi mental. Conquanto Simmel não negue a dimensão instrumental do valor de uso dos objetos, parece-lhe haver uma parte significativa deste que emerge além da mera funcionalidade. Por conseguinte, o valor de algo é resultante da dinâmica de atribuições, uma vez que engendram um jogo entre ter e não ter, trazendo consigo uma clara prerrogativa social psicológica.
Eis o porquê, por exemplo, de o colecionador não gozar necessariamente com a posse dos objetos que possui, mas com o planejamento e o ato da compra. Após o ato, ocorre a mortificação dos objetos adquiridos. É preciso articular a dimensão presente e possível para compreender a construção cultural e social do valor. Por conseguinte, ele não é uma unidade, ou seja, uma propriedade fixa dos objetos (Simmel, 2009), mas uma projeção intersubjetiva mediada por classificações, hierarquias e convenções culturais.

Tendo em vista esta elaboração argumentativa, se o valor é uma relação, ele é simultaneamente um ato. Assim que a mente não mais permanece como mero espelho desinteressado da realidade, emerge da valoração uma forma objetiva de conhecimento, materializando-se numa ordem simbólica autônoma. O autor argumenta: "Em cada momento, no qual nossa mente não é simplesmente o reflexo desinteressado da realidade - o que ela talvez nunca tenha sido, pois mesmo o conhecer objetivo surge tão somente de uma valoração da realidade - ela vive no mundo dos valores, que compreende os conteúdos da realidade numa ordem totalmente autônoma" (Simmel, 2009, p. 23, tradução nossa). ${ }^{7}$ Valorações conformam o substrato psíquico e afetivo das sociações. Cabe recordar que só há valoração se houver interesse (em relação a "algo"). ${ }^{8}$ Em decorrência disso, toda ação contém, segundo Simmel, um vetor teleológico, uma direção imbricada numa rede de interações e associações.

Ao projetarmos (Vorstellung) intelectualmente os objetos na realidade, distanciamo-nos deles como sujeitos. Isso ocorre porque o valor de algo supõe a postergação do gozo imediato (Simmel, 2009). Com isso, as valorações surgem

\footnotetext{
${ }^{7}$ No original: "In jedem Augenblick, in dem unsere Seele kein bloßer interesseloser Spiegel der Wirklichkeit ist- was sie vielleicht niemals ist, da selbst das objektive Erkennen nur aus einer Wertung seiner hervorgehen kann - lebt sie in der Welt der Werte, die die Inhalte der Wirklichtkeit in eine völlig autonome Ordnung faßt”.

${ }^{8}$ Vale a pena notar que muito embora o binômio indivíduo/ ação social não configure a unidade básica da sociologia simmeliana, o que se poderia chamar de "ação social" detém uma natureza teleológica referente à origem (terminus ad quem) ou à finalidade (terminus ad quo) (Simmel, 2009).
} 
do distanciamento entre sujeito e objeto, consolidando-se num processo de diferenciação (Simmel, 2009). Quanto mais curto e simples é o encadeamento dos meios para se transformar expectativa e anseio em satisfação, menos complexa e diferenciada é a relação sujeito e objeto. Assim, Simmel quer chamar atenção ao fato de que a emergência de um espaço psicossocial mediado por expectativas e anseios é tão mais forte e premente quanto mais distanciada se torna a diferenciação entre sujeito e objeto, relativizando a dimensão propriamente instintual e imediatamente fisiológica dos impulsos (Simmel, 1896a, 1908). No entanto, esta teoria genética do valor, elucubrada enquanto dinâmica de distância e engajamento entre sujeito e objeto, deve ser enquadrada como componente das interações intersubjetivas (Simmel, 2009). Enquanto valorações se confirmam como projeções que se externalizam em contextos sociativos, se tornando coletivamente comensuráveis, sua motivação inicial pode residir no âmbito da psicologia individual. Desse modo, tudo leva a crer que certo arranjo de nossa economia emocional permite maneiras de projetar e esquematizar os objetos e os outros, influenciando o transcorrer das interações. Num contexto interacional, a valoração comporta simultaneamente circunspecção cognitiva e densidade afetiva, não permitindo-nos abdicar da formulação de uma categoria de personalidade perpassada por cognição e impulsos.

Logo, a capacidade da consciência prática em projetar intelectualmente o mundo exterior é acompanhada por uma economia afetiva aderente aos valores objetivados, os quais necessitam de reconhecimento: "O valor aguerrido em alguma coisa, pessoa, numa relação ou num acontecimento, almeja ser reconhecido" (Simmel, 2009, p. 37, tradução nossa). ${ }^{9}$ Simmel quer chamar atenção não apenas à energização afetiva dos valores, moldando hábitos, práticas e percepções, mas ao fato de que estes

${ }^{9}$ No original: "Der Wert, der an irgendeinem Dinge, einer Person, einem Verhältnis, einem Geschehnis haftet, verlangt es, anerkannt zu werden". engendram algum tipo de reconhecimento relacionalmente posto, seja ele tácito ou explícito. O valor é, pois, a atribuição significativa resultante de sua posição no ordenamento das ideias e de uma cultura. ${ }^{10}$ Dessa maneira, ele é uma categoria metafísica, dado que não é concretamente apreensível, apenas em suas manifestações secundárias. Entendida como diferenciação entre sujeito e objeto, a teoria do valor procura demonstrar a maneira pela qual a objetivação de atribuições repousa, em parte, em motivações psíquicas e pulsionais, que vêm a dimensionar o curso de nossas ações e avaliações num contexto de interação.

É notório que, na trajetória intelectual de Georg Simmel (Rammstedt, 1993; Vandenberghe, 2005; Waizbort, 2000) há uma gradual transição da ótica neokantiana, preocupada predominantemente com as formas e conteúdo da sociação, ao vitalismo, que toma a vida como categoria central. Contudo, na obra simmeliana, este caminho não exclui a eclosão de tais temáticas (possivelmente de maneira menos sistemática) ao longo de seus escritos (Aron, 1981 apud Vandenberghe, 2005). Parece-nos então que, em maior ou menor grau, sempre houve de sua parte preocupação em compreender fenômenos coletivos como sendo compostos por elementos racionais e irracionais; cognitivos e afetivos. No curso das interações sociativas, a personalidade se deixa estratificar por motivações afetivas e outras conscientes. Muito embora a proeminência de uma sobre a outra dependa do conteúdo das interações, as duas dimensões estão articuladas.

Isso parece se manifestar na maneira como Simmel trabalha com a noção de personalidade, que articula um nível de formalização, referido às interações e à sociação, a um nível subjetivo, referido aos conteúdos intrapsíquicos que animam a vida em sociedade. Ao nível da formalização, Simmel (1992) busca fundamentar as três pré-condições (a priori)

${ }^{10}$ No entanto é necessário pontuar que a gênese dos valores e distincões qualitativas não se insere propriamente no panorama de uma teoria historicamente situada da cultura, mas no espectro de uma antropologia filosófica. 
dos processos de socialização (Sozializierungsprozesse). Tais pré-condições - embora passíveis de uma reconstrução lógica enquanto esquemas capazes de dar forma à experiência - constituem saberes de ordem prática (Simmel, 1992). A primeira pré-condição das relações é a alteridade. Para Simmel (1992), as percepções dos outros enquanto seres com os quais se interage com densidade afetiva não constituem um dado trivial, mas sim o resultado de operações de generalização a partir de fragmentos aparentes e comunicáveis, já que a individualidade pessoal de outrem escapa à sua representação completa por nós. Com isso, tais generalizações são baseadas em uma miríade de fragmentos empíricos contextuais que permitem nosso senso prático projetar a imagem de outrem de modo categorizado. Nessa dimensão do entendimento, o caráter esquemático da imagem sensível do outro se alia à qualidade funcional desempenhada num dado contexto institucional. Nas interações, não tipificamos nossos pares como indivíduos abstratos, mas como colegas, esposa, camaradas de partido, patrão, empregado etc. Quando um cidadão se vê perante um oficial: " ele não pode se desvencilhar do fato de que este indivíduo é um oficial" (Simmel, 1992, p. 50, tradução nossa). ${ }^{11}$

Ao lado dessa capacidade de síntese que faz emergir o ser socializado (Vergesellschafet-sein) (Simmel, 1992), existe uma segunda নิ pré-condição dos processos de socialização. o. Do ponto de vista estrito da performance funcional, em nossa percepção de outrem sempre há, no entanto, um elemento extrassocial (AusA sersozial) da individualidade, o qual não pode ¿ ser apreendido através de esquematizações geÆ̛ं neralistas. Essa espécie de sobra do outro não

$\dot{s}$ é, contudo, esquematizada de maneira residual, mas sim como a dimensão não socializada do outro. Esse ser não socializado é apreendido como aquilo que confere propriamente

${ }^{11}$ No original: “Der Bürgerliche, der einen Offizier kennenlernt, kann sich garnicht davon freimachen, dass dieses Individuum ein Offizier ist". singularidade ao outro. Trata-se do elemento que engloba peculiaridades, nuances e variações pessoais no intercâmbio intersubjetivo. A forma do ser socializado é codeterminada pela dimensão não socializada da personalidade (Simmel, 1992), de modo a coordenar a tonalidade das interações.

Esta experiência "dual", na qual o desempenho de um papel social não se confunde com os atributos pessoais mais irredutíveis da personalidade, é tão mais forte quanto mais socialmente diferenciadas são as posições desempenhadas nas sociações. Em esferas como a economia monetária capitalista ou na burocracia estatal, aquele que desempenha um papel aproxima-se da pura objetividade (Simmel, 1992), dado que os imperativos funcionais de uma posição precedem a pessoa. Da mesma forma, as regras obedecidas objetivam-se, tornando-se mediadas por acordos institucionais impessoais, expressados, por exemplo, no direito, além de outras formações culturais objetivadas, relativamente independentes de seus portadores imediatos, como a linguagem, a matemática etc. (Simmel, 1992). Aqui, também ecoa paralelamente o tema a respeito da intelectualização da cultura, acompanhado pelo aumento do poderio sintético da consciência.

Por fim, dentro deste enquadramento, o último a priori sociológico dos processos de socialização residiria na própria apreensão de um todo coletivo, quer dizer, na representação da sociedade como um organismo racional e harmônico, baseado na especialização funcional e na complementaridade entre os imperativos funcionais de cada posição na divisão do trabalho. Do ponto de vista de uma estética sociológica (Simmel, 1896b) o organismo coletivo surge como artefato técnico. Todavia, enquanto objetividade realizada, o ideal de sociedade jamais encontra correspondência empírica perfeita, uma vez que esta é imperfeita, dinâmica e lacunar. Assim, para Simmel, há sempre algo que escapa, de modo fugidio, à rotinização total da vida social. Em sua ótica, o organismo social não constitui uma entidade 
sui generis a ser tratada como categoria de análise, mas uma forma nativa de esquematização da vida coletiva.

Outra seara em que se observa a preocupação de Simmel com a dimensão racional e afetiva concerne às duas principais vertentes de individuação que o autor identifica na modernidade, sinteticamente formuladas em Kant e Goethe (Simmel, 1995). Nossa experiência é cindida em mente e corpo; pela experiência do indivíduo na natureza ou pela sociedade (Simmel, 1995). Segundo Simmel, a raiz da cisão entre sujeito e objeto - assim como entre mente e corpo - reside na herança ocidental cristã (Simmel, 1995).

Aí repousaria a grandeza da teoria do sujeito de Kant: ela permitiria não diluir o sujeito à materialidade do mundo exterior. Kant concilia o subjetivo e o objetivo por uma ideia de consciência estratificada, tomando como referencial da atividade cognoscente o cientista e o filósofo analítico (Simmel, 1995). Os objetos se prestam ao conhecimento mediante esquematizações operadas por categorias da percepção e do entendimento. Essas categorias operam de maneira pré-reflexiva, no sentido estrito de darem forma à experiência sensível independentemente de uma auto-observação (consciência para si). Uma maneira mais adequada de designar sua atuação, contudo, está em dizer que elas correspondem a uma infraestrutura da atividade consciente.

Em Goethe, Simmel observa uma compreensão contrastante. Para aquele autor, a infraestrutura da atividade consciente não consiste numa arquitetura logicamente consistente da percepção e do pensamento, mas antes num manancial de emoções vitais que permeiam a experiência com o mundo sensível. Enquanto Kant toma o cientista e o filósofo analítico como referências da atividade consciente, Goethe toma o artista, centrando sua acepção sobre a consciência na ideia de uma cumplicidade ontológica e afetiva com o mundo externo (Simmel, 1995). Os afetos antecipam-se ao pensamento racional. Eles condi- cionam nossos pensamentos e representações. Por isso, a atividade laboral artística caracteriza-se pela entrega da subjetividade artística à obra de arte. Certamente, aqui entra em cena a noção romântica da inspiração, tendendo a tornar a produção, o consumo e o gozo artístico em desempenhos privados isentos de pressões externas (Elias, 2005; Schilling, 1966).

Ao racionalismo kantiano contrapõe-se (de modo complementar) o vitalismo goethiano. À estética racional, entendida enquanto coordenadas que balizam a percepção de eventos - de outra feita imperscrutáveis - contrapõe-se a estética como expressão de uma relação de comunhão, tanto solidária quanto tensa, com o mundo exterior. A natureza não é mais, como em Kant, uma unidade virtual projetada no mundo pelas categorias de percepção, mas uma realidade sui generis na qual o sujeito está imerso (Simmel, 1995). O mundo objetivo não é, então, desencantado pela ciência, mantendo via arte sua prerrogativa irredutível à lógica formal.

Tais faculdades afetivas não negam, para Goethe, qualquer possibilidade epistêmica, mas, ao contrário, constituem elas próprias mananciais de conhecimento, pois: " $a$ destruição da imagem estética significa, para ele, a destruição da verdade" (Simmel, 1995, p. 142, tradução nossa). ${ }^{12} \mathrm{O}$ conhecimento expressivo, na medida em que se dirige à qualidade e à singularidade dos objetos, não destrói sua beleza, pois ela seria substância do real (Simmel, 1995). O moderno ideal do estilo pessoal como uma intenção consciente de um projeto estético exprime, para Goethe, uma objetividade, além de refletir uma outra forma de acesso à verdade, enquanto expressão de um atributo imanente. Assim, a objetividade daquilo que nos circunda é irredutivelmente energizada. Não por acaso, a atividade artística depende de um estado de eudaimonia, isto é, do ato de estar possuído, construindo uma relação suprassensível entre artista e obra. O artista deve aceitá-la como parte de sua intera${ }^{12}$ No original: "Die Zerstörung des ästhetischen Bildes ist ihm die Zerstörung der Wahrheit". 
ção com o mundo, dado que: "onde esta incomensurabilidade busca elevar-se à consciência completa, o Homem sucumbirá” (Simmel, 1995, p. 161, tradução nossa). ${ }^{13}$

As ideias de Kant e Goethe encontram, de fato, ressonância na teoria do valor de Simmel, uma vez que a projeção representativa de objetos engloba não a indiferença afetiva com relação a estes, mas justamente um sentimento valorativo (Wertgefühl) (Simmel, 2009). Do mesmo modo, o grau de energização e engajamento afetivo, identificáveis nos conteúdos sociológicos, dependerá tanto do nível de formalização da interação, bem como da esfera de valor em questão. Esferas marcadas por um edifício maior de formas mediando as interações com os outros e com o mundo, como o mercado moderno, por exemplo, tendem a ditar a mobilização mais intensiva das camadas mais reflexivas e menos energizadas da vida consciente. Não que as valorizações afetivas não tenham um papel na gênese dos valores em jogo. Apenas essa gênese se encontra, por assim dizer, recalcada na medida em que a atividade subjetiva está voltada para a adequação a toda uma cadeia de formas que medeiam a relação com os fins.

\section{REFLEXÕES CONCLUSIVAS}

O que procuramos mostrar é como Simసิ mel mobiliza uma psicologia social para artio. cular uma sociologia geral, cujo tema central é $\stackrel{5}{D}$ a dialética entre indivíduo e cultura, ao plano ¿ै de uma sociologia formal das interações. Essa $\stackrel{7}{7}$ psicologia social procura identificar como uma $\dot{2}$ dinâmica entre racionalidade e afetos permeia Æ̛ં essa articulação. Há uma noção de consciên-

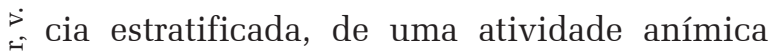
subjetiva com camadas mais profundas, mais energéticas e passionais, e camadas superiores, menos energéticas e mais reflexivas. Por um lado, toda a dinâmica dessa atividade sub-

${ }^{13}$ No original: "Wo diese Inkommensurabilität zu vollem Bewusstsein gelangt, muss der Mensch untergehen". jetiva é analisada por Simmel em relação aos contextos de interação que medeiam a produção e a apropriação dos elementos da cultura. Por outro lado, todo esse processo de produção e de apropriação é interpretado tendo em vista essa atividade subjetiva, o que confere o teor "psicologizante" de suas análises. Isso fica claro em suas construções de tipos sociais, como o blasé. O estágio de evolução de formas, como o dinheiro na vida moderna e, de maneira mais geral, a complexidade e a dinâmica das interações na grande cidade constituem o dado sociológico principal nessa construção do autor. Ao mesmo tempo, o blasé é caracterizado a partir da análise psicológica de um tipo específico de economia emocional, que responde por uma adaptação do indivíduo a esse ambiente. A análise de Simmel sobre o blasé associa as metrópoles, entendidas enquanto loci social da modernidade, a um estado mental distanciado decorrente do intenso bombardeamento de sensações e informações do ambiente coletivo circundante.

A discussão de Simmel sobre a diferenciação social também é profundamente marcada pelo papel auxiliar que uma psicologia social cumpre em suas análises. Como os outros clássicos, Simmel considera essa diferenciação uma das mais importantes características da modernidade. Contudo suas considerações se deslocam do tema da integração social, como em Durkheim, ou da pluralização das matrizes de sentido para a ação, como em Weber. Simmel remete a diferenciação social à diferenciação entre contextos de interação em termos das camadas da vida subjetiva que estes mobilizam. Esferas com maior nível de formalização mobilizam as camadas menos energéticas e mais racionais, dando ênfase ao ser socializado ao mesmo tempo em que, complementarmente, mantêm ao máximo a reserva do ser não socializado. Por outro lado, nas relações de amizade, familiares ou erótico/ amorosas, tal reserva individual, como contraponto aos imperativos funcionais do desempenho impessoal, se enfraquece (Simmel, 2009). 
Nelas, a necessidade de engajamento pessoal é mais forte, em razão da expectativa de engajamento afetivo. Nessas esferas, a recorrência de um comportamento instrumental não é apenas considerada estranha, assim como pode trazer sérias sequelas para quem dele é objeto.

É o caso da prostituição (Simmel, 2009). Se as relações erótico/amorosas pressupõem a mobilização das camadas mais afetivas da vida subjetiva e uma correlata aproximação entre o ser socializado (o papel social) e o ser não socializado (a idiossincrasia e a devoção pessoal) na interação, a mediação da interação e da relação entre meios e fins pela forma dinheiro reinsere o distanciamento entre o ser socializado e o ser não socializado. Ainda que na prostituição, pelo menos do ponto de vista do cliente, a interação tenha por finalidade o atendimento a um conteúdo pulsional, altamente energético, o tipo de mediação reenvia a atividade subjetiva para a camada do cálculo racional, implicando em distanciamento. Do ponto de vista das interações, a intimidade reside exatamente na aproximação entre ser socializado e o ser não socializado. A intimidade enquanto fenômeno subjetivo, que se apresenta enquanto uma indiferenciação entre cálculo e afeto na origem das escolhas, é a contraface daquela aproximação.

Simmel sustenta que, distintamente da psicologia individual, cujos objetos são processos mentais intrapsíquicos, os objetos específicos da psicologia social seriam, por um lado, produtos de inquestionável aderência mental (Seelenhaftigkeit) existentes na sociedade. Por outro, tais constructos mentais seriam relativamente independentes de seus portadores individuais empíricos (Simmel, 1992). Assim, os conteúdos simbólicos objetivados da cultura exigem um terceiro elemento, que, além de não se deixar reduzir em nenhum exemplar individual, não repousa numa lógica psicológica. Há, portanto, a necessidade de se investigar a gênese e a eficácia desses conteúdos na vida social - a partir de sua relação com os fenômenos da vida subjetiva.
Concluímos que mais do que uma mera circunscrição arbitrária de domínios de conhecimento, Simmel procurou ressaltar o caráter relacional entre psicologia individual, psicologia social e sociologia. Constatamos, por fim, que, em sua visão, mais do que tecnicalidades diminutas - por vezes estéreis - entre as especialidades disciplinares, as diferenças entre elas se dão muito mais na maneira de construção do objeto do conhecimento científico. É na especificidade do fim da construção do objeto do conhecimento, a partir do qual cada domínio disciplinar emerge, que se localiza a questão principal. A contribuição aqui proposta teve como objetivo principal atualizar Simmel em relação a discussões sociológicas contemporâneas, como o elo entre tendências pré-reflexivas à ação e formas de classificação, assim como ação e estrutura. Descobriu-se que sua sociologia das formas sociativas jamais deixou de entender as interações intersubjetivas como processos psíquica e afetivamente energizados.

Assim, percebemos a preocupação de Simmel em esclarecer o significado sociológico de seu interesse pela psicologia através de sua teoria do desenvolvimento cultural, da gênese dos valores e da personalidade.

Recebido para publicação em 02 de abril de 2020 Aceito em 13 de setembro de 2021

\section{REFERÊNCIAS}

ARON, R. As etapas do pensamento sociológico. São Paulo: Martins Fontes, 1993.

BOUDON, R. Erkenntnistheorie in Georg Simmels philosophie des geldes. In: KINTZELE, J.; SCHNEIDER, P (org.). Simmels philosophie des geldes. Frankfurt am Main: Anton Hain, 1993. p. 113-143.

BUENO, A. Do singular ao comum? Simmel e as tensões da individualidade moderna. Revista Inter-Legere, Natal, v. 2, n. 24, p. 81-117, 2019.

COHN, G. As diferenças finas: de Simmel a Luhmann. Revista Brasileira de Ciências Sociais, São Paulo, v. 13, n. 38, p. 53-62, 1998 .

DURKHEIM, É. Da divisão do trabalho social. São Paulo: Martins Fontes, 2008.

ELIAS, N. Mozart: zur soziologie eines genies. Frankfurt am Main: Suhrkamp, 2005. 


\section{O LUGAR DA PSICOLOGIA SOCIAL EM GEORG SIMMEL}

FRISBY, D. Simmel and social psychology. In: Simmel and since: essays on Simmel's social theory. New York: Routledge, 1992. p. 15-31.

GROSSWÖRTERBUCH, S. Pons. Berlin: Verlag, 2011.

KRACAUER, S. Gerog Simmel. In: Das ornament der masse. Frankfurt am Main: Suhrkamp, 1977. p. 209249.

NEDELMANN, B. "Psychologismus" oder Soziologismus der Emotionen? Max Webers kritik an der soziologie Simmels. In: RAMMSTEDT, O. (org.). Simmel und die frühen soziologen: nähe und distanz zu Durkheim, Tönnies und Max Weber. Frankfurt am Main: Suhrkamp, 1988. p. 11-36.

RAMMSTEDT, O. Simmels Philosophie des Geldes. In: KINTZELÉ, J.; SCHNEIDER, P. (hrsg.). Simmels philosophie des geldes. Frankfurt am Main: Anton Hain, 1993. p. 13-47.

ROSA, H. Beschleunigung: die veränderung der zeitstrukturen in der moderne. Frankfurt am Main: Suhrkamp, 2005.

SCHILLING, K. Geschichte der sozialen ideen: individuum, gemeinschaft, gesellschaft. 2. ed. Stuttgart: Alfred Kröner, 1966.

SELL, C. E. Weber e o átomo da sociologia: um individualismo metodológico moderado? Civitas - Revista de Ciências Sociais, Porto Alegre, v. 16, n. 2, p. 323-347, 2016.

SIMMEL, G. Skizze einer Willenstheorie. In: EBBINGHAUS, H.; KÖNIG, A. (org.). Zeitschrift für psychologie und physiologie der Sinnesorgane, [s. l.], v. 9, p. 206-220, 1896a.

. Soziologische ästhetik. Die Zukunft, [s. l.] v. 17, n. 5, p. 204-216, 1896b.
. Über das Wesen der Sozialpsychologie. Archiv für Sozialwissenschaft und Sozialpolitik, [s. l.], v. 26, n. 2, p. 285-291, 1908.

Aufsätze 1887 bis 1890: uber die soziale differenzierung. Frankfurt am Main: Surhkamp, 1989. Schopenhauer
Sammling Junius, 1990

Soziologie: untersuchungen über die formen der vergesellschaftung. Frankfurt am Main: Suhrkamp, 1992.

Philosophie der mode, die religion, Kant und Goethe. Frankfurt am Main: Suhrkamp, 1995.

. O conceito e a tragédia da cultura. In: SOUZA, J; OELZE, G. (org.). Simmel e a modernidade. Brasília, DF: UnB, 2005. p. 77-105.

. Die Grö $\square$ städte und das geistesleben. Frankfurt am Main: Suhrkamp, 2006.

. Philosophie des geldes. Köln: Anaconda, 2009.

A tríade. In: COELHO, M. C (org.). Estudos sobre interação: textos escolhidos. Rio de Janeiro: Uerj, 2013. p. 45-75.

VANDENBERGHE, F. As sociologias de Georg Simmel. Belém: EDUFPA, 2005

WAIZBORT, L. As aventuras de Georg Simmel. São Paulo: Editora 34, 2000.

Formação, especialização, diplomação: da universidade ao ensino superior. Tempo Social, São Paulo, v. 27, n. 2. p. 45-74, 2015.

WEBER, M. Metodologia das ciências sociais. São Paulo: Cortez, 2016. 


\section{THE PLACE FOR SOCIAL PSYCHOLOGY IN GEORG SIMMEL'S WORK}

\author{
Emerson Ferreira Rocha \\ Ricardo Visser
}

The article debates the theoretical locus of social psychology in Georg Simmel's writings. The text intends to approach this problematic in four ways: I) a general reconstruction of the place of social psychology in Simmel's work; II) an appreciation of the link between the emergence of modern culture and the psychological energizing of individual experience; III) a reconstruction of how he took similar theoretical pathways in his value theory, in which subject and object differentiate themselves by the distancing between enjoyment and its object; IV) lastly a recollection of how Simmel concerned himself with understanding the dialectics of subject and object from a point of view capable of relating cognition and drive. We expect this discussion to help to illuminate the sociological meaning of his interest on psychology by means of his theory of cultural development, of genesis of values, and of personality.

Keywords: Sociological Theory. Social Psychology. Georg Simmel. Modern Culture. Personality.

\section{LA PLACE DE LA PSYCHOLOGIE SOCIALE CHEZ GEORG SIMMEL}

\author{
Emerson Ferreira Rocha \\ Ricardo Visser
}

L'article propose une discussion sur le lieu de la psychologie sociale chez Georg Simmel. Le texte a l'intention d'introduire ce debat de quatre manières : I) une reconstruction générale sur la place de la psychologie sociale dans l'oeuvre de Simmel ; II) une analyse sur le rapport entre l'emergence de la culture moderne et l'energisation psychologique de l'expérience individuelle ; III) une reconstruction sur comment il a pris des directions similaires dans sa théorie de la valeur, dans laquelle sujet et object se différencient par la distance entre la jouissance et son objet ; IV) finalement, un rappel à la préocupation théorique de Simmel pour comprendre la dialectique entre sujet et objet d'un point de vue capable de relationner cognition et pulsion. Nous espérons que cette discussion allume le sens sociologique de l'intérêt de Simmel pour la psychologie au moyen de sa théorie du dévéloppment culturelle, de la valeur et de la personnalité.

Mots-CLÉs: Théorie Sociologique. Psychologie Sociale. Georg Simmel. Culture Moderne. Personnalité.

Emerson Ferreira Rocha - Doutor em Sociologia pela Universidade de Brasília e professor adjunto do Departamento de Sociologia da Universidade de Brasília. Publicou o artigo "Espaço social e estrutra de classes em regiões metropolitanas brasileiras”, na revista Sociedade e Estado, em 2018.

Ricardo Visser - Doutor em Ciências Sociais pela Universidade Federal de Juiz de Fora e professor adjunto de Ciências Sociais na Universidade Federal de São João del-Rei. Publicou, em 2017, o artigo "A sociologia econômica de Simmerl e Bourdieu: considerações para um programa de pesquisa" na Civitas: Revista de Ciências Sociais. 
